\title{
Formulation of Microemulsions for Dermal Delivery of Cephalexin
}

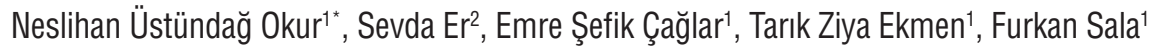 \\ 1Istanbul Medipol University, School of Pharmacy, Department of Pharmaceutical Technology, Beykoz, 34810 Istanbul, Turkey \\ ${ }^{2}$ Anadolu University, Yunus Emre Vocational School for Health Services, 26470 Eskişehir, Turkey
}

\begin{abstract}
Introduction: Cephalexin monohydrate (CEM) is mostly used because of its activity against both the gram-positive and gram-negative microorganisms for infections. Microemulsions offer numerous advantages for dermal delivery of drugs. Objective: The objective of the present study was to prepare novel CEM loaded microemulsions and to characterize formulations, to evaluate their in vitro release profiles and antibacterial activities.
\end{abstract}

Method: CEM loaded formulations [0.02\% (w/w)] were characterized according to their droplet size, zeta potential, PDI, pH, electrical conductivity and viscosity. In addition, in vitro drug release studies and antibacterial activity tests were performed.

Results: The developed CEM loaded microemulsions (M1 and M2) achieved narrow droplet size distribution $(152.75 \pm 4.85$ and $128.05 \pm 9.22)$, low PDI (0.364 \pm 0.05 and $0.489 \pm 0.06)$, suitable $\mathrm{pH}(5.28-4.84)$ and conductivity (342 $\pm 4.472-374 \pm 5.477$ $\mu \mathrm{S} / \mathrm{cm})$. Zeta potential was measured as $0.209 \pm 0.041$ and $0.141 \pm 0.024 \mathrm{mV} . \mathrm{M}_{\text {СЕM }}$ showed $100 \%$ release at the $7^{\text {th }}$ hour and was provided almost the same zone diameter as CEM solution when evaluated for antibacterial activity.

Conclusion: Overall, it was concluded that microemulsions might be beneficial in improving dermal delivery of CEM for the treatment of skin and soft tissue infections.

Keywords: Cephalexin, microemulsion, dermal delivery, in vitro release, antibacterial activity.

\section{INTRODUCTION}

Human skin is the largest organ of a human being, therefore it takes the attention of scientists as being an important target site for the application of drugs ${ }^{1}$. Topical drug delivery is an important way of treating especially local diseases due to features of these systems such as being restricted to the affected area, therefore, reducing systemic side effects and being easy to stop treatment in a

\footnotetext{
*Corresponding author: Neslihan Üstündağ Okur, e-mail: neslihanustundag@yahoo.com, Phone: +90216 6815100/5190, Fax: +090212 531755

(Received 13 July 2017, accepted 15 August 2017)
} 
proper time in case of a severe side effect ${ }^{1}$. On the other hand, dermal drug delivery is a promising way of treatment because of large surface area of skin and being easy to access and the administration route is non-invasive therefore improved patient compliance ${ }^{2}$.

In recent years, colloidal drug delivery systems especially nanocarriers range up to $500 \mathrm{~nm}$ have increased the attention of scientists for dermal drug delivery ${ }^{3}$. Microemulsions (MEs) are one of the colloidal drug delivery systems which its concept was introduced to the literature in early $1940 \mathrm{OS}^{4}$. MEs are clear, thermodynamically stable and optically isotropic mixtures which has low viscosity and consist of oil, water, surfactant and co-surfactant ${ }^{4-8}$. The main benefit of MEs is being in need of less energy whilst forming. In order MEs to be formed, a highly fluid interfacial film and latter, low interfacial tension which occurs between colloidal and the external phase are required ${ }^{5}$.

For dermal drug delivery, the main advantages of microemulsions can be divided into three groups. First, they can be a potential drug carrier system in order to dissolve both hydrophilic and lipophilic drugs therefore show increased thermodynamic activity towards skin itself. Secondly, by the effect of permeation enhancers involved in microemulsion formulation, Stratum Corneum (SC) can be destroyed and subsequently the flux of drugs via skin increases. Latter, the affinity of a drug to the internal phase can be easily modified in favor of partitioning into the SC, therefore permeation rate of drug can be improved ${ }^{9,10}$.

The most commonly occurring infections in people are skin infections ${ }^{11}$. Microbial invasions into skin and the soft tissues underneath the skin are defined as Skin and Soft Tissue Infections (SSTIs). They show variable presentations, etiologies and severities. The main obstacle of SSTIs is to conveniently differentiate those cases that have severe presentations which require immediate attention and intervention from those that are less severe. SSTIs can be produced by the extremely diverse ecology of organisms localized on the skin. The clinical manifestations of SSTIs are the sum of two-step process. The first step is microbial invasion to the host and the second step is interaction with host defences ${ }^{12}$. Gram-positive species such as Staphylococcus epidermidis, Corynebacterium species, $S$ aureus and Streptococcus pyogenes are generally the typical flora which colonize the skin. S. aureus and Streptococcus pyogenes are the main reason for SSTIs.

Cephalosporins, are the most widely used for treatment of skin infections because of their safety profiles ${ }^{13}$. Cephalexin monohydrate (CEM), (7R)-7-(D- $\alpha-$ Amino- $\alpha$-phenylacetamido)-3-methyl-3- cephem-4-carboxylic acid hydrate or $(6 \mathrm{R}, 7 \mathrm{R})-7-\{[(2 \mathrm{R})-2-a m i n o-2-p h e n y l a c e t y l] a m i n o\}-3-$ methyl-8-oxo-5-thia- 
1-azabicyclo[4.2.0]oct-2-ene-2-carboxylic acid hydrate (Figure 1), is an antibiotic which has high oral absorption and lack of serum binding ${ }^{14}$. CEM has low water solubility (less than $0.1 \mathrm{mg} / \mathrm{g}$ ) has been using in the treatment of bacteria caused infections. Meanwhile, CEM has an important role for patients who have hypersensitivity to penicillin as being an alternative ${ }^{15}$.

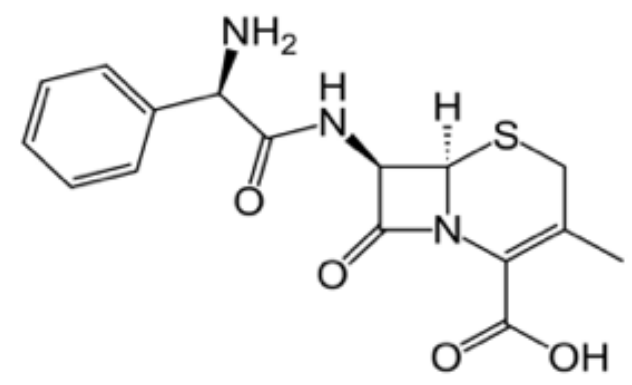

Figure 1. Structural formula of cephalexin

In addition to all mentioned above, for treatment of antibacterial infections CEM loaded microemulsions takes an important corner because of advantageous features such as avoidance of gastrointestinal side effects, increased solubility and improved targeting ${ }^{16}$. The aim of the present study was to prepare novel CEM loaded microemulsion formulations and to evaluate a better formulation of CEM for dermal delivery. For this aim, the physico-chemical characterization, in-vitro release, stability and microbiological tests were evaluated.

\section{MATERIALS AND METHODS}

\section{Materials}

CEM was purchased from DSM Sinochem, Spain. Isopyropyl myristate (IPM), Span 20 and phospate buffer tablets were purchased from Sigma, USA. Tween 80 (Polysorbate 80), and ethanol were purchased from Merck, Germany. Cremophor EL (Macrogolglycerol ricinoleate) kind gift from BASF, Germany. Oleic acid was purchased from Doga Ilac, Turkey. Dialysis membrane (Spectro/por Dialysis Mebrane, Spectra/por 4, diameter $16 \mathrm{~mm}$, molecular weight of 12-14 $\mathrm{kDa}$ ) were purchased from Spectrum. All other chemical reagents and solvents were of analytical grade and used as received.

\section{Preparation of microemulsion formulations}

In order to discover the existence range of microemulsions, pseudo-ternary phase diagrams were constructed by using titration method. A series of oil and surfactant/cosurfactant $(\mathrm{S} / \mathrm{Cos})$ mixtures with phosphate buffer at ambient temperature $\left(25 \pm 2{ }^{\circ} \mathrm{C}\right)$ were titrated. After being equilibrated, microemulsions 
were determined by visually examining the mixtures ${ }^{17}$. The phase diagrams were constructed by using a software program ${ }^{18}$. All experiments were replicated at least four times.

Two different microemulsion formulations were prepared in accordance with the microemulsion areas in the phase diagrams. The microemulsion systems were prepared using IPM and oleic acid as oil phase, Span 20, Tween 80, Cremophor EL as surfactants, ethanol as co-surfactant and phosphate buffer as aqueous phase. After gently equilibrating selected microemulsions for 5 min with magnetic stirring, appropriate amount of CEM was dissolved in these microemulsions. The final concentration of CEM in formulations was $0.02 \%(w / w)$.

\section{Characterization of microemulsion formulations}

The characteristic features of microemulsions such as $\mathrm{pH}$, viscosity, refractive index, electrical conductivity, droplet size, polydispersity index (PDI), and zeta potential was evaluated in order to discover the suitability of microemulsions for topical administration.

Dynamic Light Scattering method (Nano ZS, Malvern Instruments, U.K.) was used to measure the average droplet size and PDI. The particle size and PDI values (repeated five times at $25^{\circ} \mathrm{C}$ ) were obtained by averaging of five measurements at an angle of $173^{\circ}$ by using disposable cells.

In order to measure the zeta potential of samples, disposable plain folded capillary zeta cells (Malvern Zetasizer Nano ZS) were used. The zeta potential was calculated from the electrophoretic mobility using the Helmholtz-Smoluchowski equation under an electrical field of $40 \mathrm{~V} / \mathrm{cm}$. Software involved system was used for the process. The measurements were repeated five times at $25 \pm 2{ }^{\circ} \mathrm{C}$.

In order to measure the viscosities of formulations, AND Vibro Viscometer- SV10 as viscosimeter was used. The $\mathrm{pH}$ values of the formulations were determined by a digital $\mathrm{pH}$-meter (Mettler Toledo, Switzerland). The refractive index values of formulations were evaluated using a refractometer (Krüss DR301-95, Germany). Electrical conductivity of the formulations was studied using a conductometer (Milwaukee MW 801, USA) to determine the type of microemulsion. Experiments were performed at $25 \pm 2{ }^{\circ} \mathrm{C}$ five times for each sample, and the results are presented as mean $\pm \mathrm{SD}$.

\section{Evaluation of in vitro Cephalexin release}

A synthetic membrane (Spectro/por Dialysis Mebrane, Spectra/por 4, diameter $16 \mathrm{~mm}$, molecular weight of 12-14 $\mathrm{kDa}$ ) was filled with $3 \mathrm{ml}$ CEM loaded microemulsion formulations. The receiver compartment (37 mL) consisted of ethanol 
and PBS pH 7.4 (ratio of 20:80) in order to ensure sink condition. The receptor compartment was exposed to ambient temperature and covered with parafilm to prevent evaporation. The temperature of the receptor compartment was maintained at $37 \pm 1^{\circ} \mathrm{C}$ while the buffer solution was stirred at 6oorpm continuously with a magnetic bar. Samples $(1 \mathrm{~mL})$ were withdrawn from the release medium at predetermined times $(0,0.5,1,2,3,4,5,6$, and $7 \mathrm{~h})$. The samples were analyzed by UV-Visible spectrophotometer (UV-180o, Shimadzu, Japan) at $261 \mathrm{~nm}$. The analytical method was validated. Calibration curve was drawn.

\section{Antibacterial activity studies of CEM loaded microemulsion formulations}

Isolates of Staphylococcus epidermidis $\left(1 \mathrm{C} 1,7 \mathrm{~N}_{5}, 7 \mathrm{C}_{5}, 7 \mathrm{N6}, 7 \mathrm{~K} 9,11 \mathrm{C} 8,11 \mathrm{~K} 8\right.$ and 12K2.1) which were isolated from vaginas of healthy women and strains of S. epidermidis (ATCC 12228), S. aureus (ATCC 6538, ATCC 2593) were used to evaluate antibacterial activity of microemulsion formulations by performing disk diffusion method. All microorganism samples were incubated 24 hours in brain-heart infusion broth medium at $37^{\circ} \mathrm{C}$. The decision of the ethical committee of the study was taken from Istanbul Medipol University Ethics Committee of Non-Interventional Clinical Researches in Istanbul with the number 38 of Decision dated 11.04/2013.

Pure cultures of the microorganisms were prepared in $0.85 \%$ sterile saline solution and were adjusted to give an inoculum with an equivalent cell density to 0.5 McFarland turbidity standards. The entire surface of the Mueller-Hinton II Agar (MHA) plate (diameter, $90 \mathrm{~mm}$ ) (Bio-Rad) was covered with the required inoculum, and the plate was air dried for $15 \mathrm{~min}$ before the disks were laid on the sterile discs were then placed onto agar plates, and $5 \mu \mathrm{L}$ of every formulation was applied to the discs. Discs were $1.5 \mathrm{~cm}$ away from the side of the petri dish and $2 \mathrm{~cm}$ away from each other. Plates were incubated at $37^{\circ} \mathrm{C}$ for $24 \mathrm{~h}$, and the zone diameters of each formulation for each isolate were measured ${ }^{18-21}$.

The experimental groups were listed as:

- G1: M1 Formulation (unloaded) (F1)

- G2: M1 CEM (containing 0.02\% CEM) (F1+CPH)

- G3: M2 formulation (unloaded) (F2)

- G4: M2 CEM (containing 0.02\% CEM) (F2+CPH)

- G5: 0.02\% CEM solution (CPH)

- G6: Solvent (S) 


\section{Results and discussion}

Cephalosporins inhibit peptidoglycan cross-linkage by crossing the bacterial cell wall. They show bactericidal effect to microorganisms which contain autolysin enzymes and bacteriostatic to microorganisms that lack autolysins ${ }^{22}$. CEM is a first-generation cephalosporin antibiotic. The mainly usage of CEM in the treatment is the susceptible infections of the respiratory tract, urinary tract, and skin because of their safety profile ${ }^{23}$. CEM is mostly used because of its activity against both the gram-positive and gram negative microorganisms ${ }^{11}$.

Nowadays, for the treatment of skin infections, the oral route is being chosen for CEM usage Even though CEM has high safety profile, systemic antibiotic usage has some disadvantages such as antibiotic resistance, which is a major threat to public health, and systemic toxicity and side effects and also low concentration of drug at the site of infection ${ }^{24}$. In order to improve drug concentration at the infection site and decrease the systemic toxicity and side effects, and avoid from the bacterial resistance topical administration of CEM can be advantageous ${ }^{25}$.

In order to overcome the disadvantages of oral drug delivery for skin infections, development of novel topical drug delivery systems such as microemulsions, nanoparticles, liposomes etc. would be helpful ${ }^{26}$. In this context, microemulsions shows favorable characteristic features because of having the simple and economical preparation method, showing long term stability, biocompatibility and high solubility of poorly soluble drugs ${ }^{1}$. For instance, it is not possible to use CEM in the treatment of some specific skin infections such as acne due to the very decreased penetration of CEM which has hydrophilic structure into the microcomedones where bacteria are located ${ }^{27}$. On the other hand, because of structural features of microemulsions, they enhance the penetration of drug into the skin and improve the dermal bioavailability with a good topical tolerance ${ }^{2}$.

In our present study, it was aimed to prepare of the microemulsions for the treating of bacterial skin infections.

\section{Preparation of CEM loaded microemulsion formulations}

In order to prepare microemulsions, IPM and oleic acid were selected as oil phase. IPM has a strong permeation enhancing effect and can increase the diffusion coefficient in skin ${ }^{28}$. Meanwhile, oleic acid which is one of the fatty acids is able to induce lipid fluidization as well as phase separation within the membrane and so enhance the permeation through skin ${ }^{29}$. In addition, to prepare microemulsions, high concentration of surfactants and co-surfactants are necessary to develop these diagrams and latter to determine the microemulsion region. This is the reason why determining the dermal tolerance of these systems is an 
important procedure to eliminate the possibility of irritation. In order to prepare microemulsions which have ideal formulation characteristics, Span 20, Tween 80 and Cremophor EL as nonionic surfactants that are considered as less toxic compared to ionic ones were investigated for their suitability to form a microemulsion ${ }^{30}$. Meanwhile, ethanol which is commonly used in dermal microemulsions was used as a cosurfactant to prepare CEM loaded microemulsions.

In order to prepare ideal microemulsions, the optimum concentration range of components involved in microemulsion itself should be determined. The construction of phase diagrams makes it easy to find out required the concentration range of components. The construction of pseudo-ternary phase diagrams was used to obtain appropriate concentration ranges of components in the areas of forming microemulsions. Gravity center of phase diagrams provided the percentage of components in order to prepare the drug free microemulsion formulations. It was seen that all formulations formed clear and transparent. Figure 2 shows the pseudo-ternary phase diagrams of drug free microemulsions. Compositions of microemulsion formulation according to the pseudo-ternary phase diagrams and area values were presented in Table 1. The area of M1, M2 microemulsions was determined as 732 and 652 respectively. M1 microemulsion has higher area than the other microemulsion. Once CEM [0.02\% (w/w)] was dissolved in the formulations, inversion of microemulsion, which is an unwanted conversion, was not seen.

Table 1. Composition of microemulsion formulations (M1 and M2)

\begin{tabular}{|c|c|c|}
\hline Components (\%) & M1 & M2 \\
\hline IPM & 21 & - \\
\hline OA & - & - \\
\hline Span 20 & 12.7 & 40 \\
\hline Tween 80 & - & - \\
\hline Cremophor EL & 24.3 & 20 \\
\hline Ethanol & 18.7 & 26 \\
\hline Phosphate buffer (pH: 7.4) & 23 & \\
\hline
\end{tabular}

* For both formulations, surfactant/co-surfactant ratio=2:1 


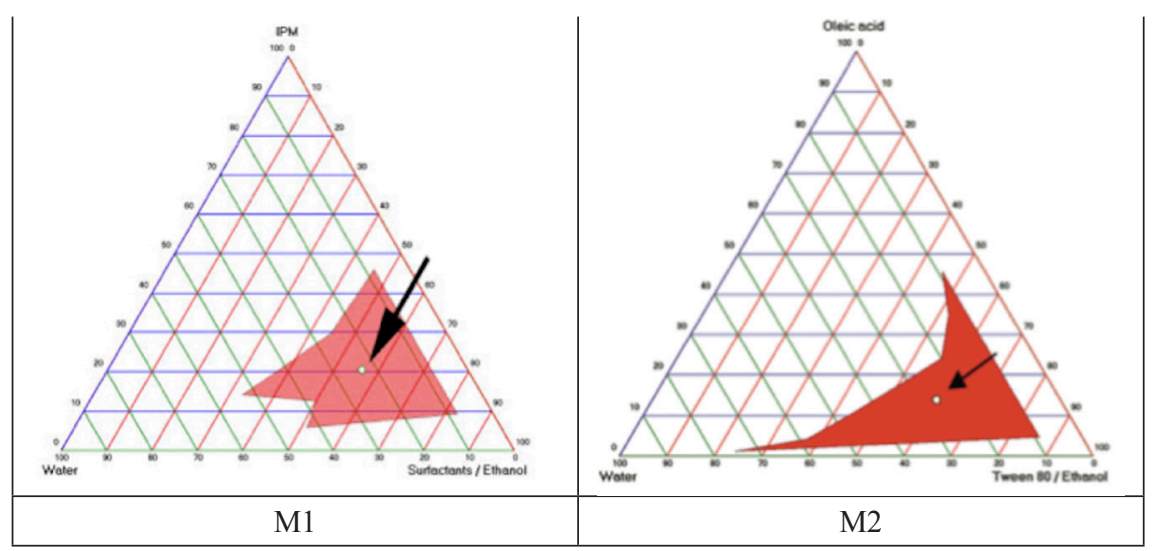

Figure 2. The pseudo-ternary phase diagrams of microemulsion formulations (M1 and M2) composed of IPM, oleic acid, Span 20, Cremopor EL, Tween 80, ethanol and phosphate buffer (pH: 7.4).

\section{Characterization of microemulsions}

Droplet size, PDI, zeta potential, $\mathrm{pH}$, viscosity, refractive index and electrical conductivity were measured in terms of determining the physicochemical properties of each microemulsion. Table 2 shows the physicochemical parameters and characteristic features of microemulsions during the presence and the absence of CEM.

The droplet size of CEM loaded microemulsion formulations were found different than each other and was determined in between $102.110 \pm 9.966 \mathrm{~nm}$ and $152.750 \pm 5.321 \mathrm{~nm}$. The present droplet size of current formulations are in the usual microemulsion droplet size range 20. The incorporation of CEM into M1 microemulsion significantly increased the droplet size ( $\left.\mathrm{p}_{5}<0.05\right)$. Different droplet size of the formulations can be interpreted in the manner of difference optimized oil and surfactants phases used. Optimization of different surfactant and oil phases may cause the minimal droplet size distribution with narrow PDI. Narrow PDI value shows the homogeneity of the size distribution of droplets in the developed microemulsions. This is the reason why the polydispersity index below 0.5 of all formulations developed can be formed an estimate of the indication of uniformity of the droplets. Zeta potential values of microemulsions were found almost neutral due to microemulsion components like nonionic surfactants.

The conductivity of CEM loaded microemulsion formulations was found between $342 \pm 4.472 \mu \mathrm{S} / \mathrm{cm}$ and $374 \pm 5.477 \mu \mathrm{S} / \mathrm{cm}$. In terms of dermal application, oil-in-water type microemulsion formulations are mostly required. According to electrical conductivity studies performed in this study, it shows that developed formulations are also oil-in-water type and are suitable for dermal applications of CEM. The refractive indexes of all microemulsions were ranged between 1.415 and $1.418 \pm 0.0002$ and thus signify that prepared microemulsions were clear and transparent. 
Table 2. Characterization of the developed blank and CEM loaded microemulsion formulations (Mean \pm S.D., $n=5$ ).

\begin{tabular}{|c|c|c|c|c|c|c|c|}
\hline 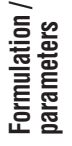 & $\mathrm{pH}$ & Droplet size (nm) & PDI & $\begin{array}{l}\text { Zeta potential } \\
\quad(\mathrm{mV})\end{array}$ & $\begin{array}{l}\text { Refractive } \\
\text { index }\end{array}$ & $\begin{array}{c}\text { Conductivity } \\
(\mu \mathrm{S} / \mathrm{cm})\end{array}$ & $\begin{array}{l}\text { Viscosity } \\
\text { (cP) }\end{array}$ \\
\hline M1 & $4.796 \pm 0.053$ & $3 \quad 65.45 \pm 1.497$ & $0.127 \pm 0,091$ & $0.325 \pm 0.047$ & 1.415 & $374 \pm 5.477$ & $104.4 \pm 0.548$ \\
\hline$M 1_{\text {CEM }}$ & $4.844 \pm 0.013$ & $3152.750 \pm 5.321$ & $0.364 \pm 0.053$ & $0.209 \pm 0.041$ & $1.416 \pm 0,0002$ & $362 \pm 4.472$ & $104.2 \pm 0.447$ \\
\hline M2 & $5.479 \pm 0.013$ & $3 \quad 150.1 \pm 1.019$ & $0.166 \pm 0.007$ & $-0.105 \pm 0.068$ & $1.418 \pm 0,0002$ & $352 \pm 4.472$ & $139.2 \pm 0.447$ \\
\hline M2 cEM & $5.287 \pm 0.027$ & $7102.110 \pm 9.966$ & $0.489 \pm 0.062$ & $0.141 \pm 0.024$ & $1.418 \pm 0,0002$ & $342 \pm 4.472$ & $134 \pm 0$ \\
\hline
\end{tabular}

All formulations were found clear on visual inspection. In terms of patient compliance, $\mathrm{pH}$ values of prepared formulations should always be taken in consideration for preventing irritating sensations. The $\mathrm{pH}$ values were found in between $4.796 \pm 0.053$ and $5.479 \pm 0.013$. Ideally, dermal formulations should possess $\mathrm{pH}$ in the range of 4-7, for minimizing discomfort of patient or irritation on the skin due to acidic $\mathrm{pH}$ and microbial growth on the skin because of basic $\mathrm{pH}^{20}$. Table 2 shows that $\mathrm{M} 2_{\text {CEM }}$ has higher viscosity compared to $\mathrm{M} 1_{\text {CEM }}$. This result can be interpreted that $\mathrm{M} 2_{\mathrm{CEM}}$ would be expected of controlled releasing drug content during in vitro studies. The results of characterization study indicate development of successful CEM loaded microemulsion formulations with optimum characteristics.

\section{In vitro CEM release studies}

The samples were analyzed by UV-Visible spectrophotometer (UV-180o, Shimadzu, Japan) at $261 \mathrm{~nm}$. The analytical method was validated in terms of analyzing the samples. Calibration curve was created with eight-point calibration concentration with the range of 0.001-0.2mg/mL for standard solution of bulk CEM. Three independent determinations were performed at each concentration. Linear relationship between absorption and concentration of CEM was observed. The standard deviation of the slope and intercept were low. The determination coefficient $\mathrm{R}^{2}$ for regression line is 0.99854 with slope of 20.624x and $y+$ intercept of +0.0149 for standard solution of CEM.

CEM loaded microemulsion formulations and CEM solution component were studied for in vitro release through synthetic membrane to assess and compare the performances of formulations. Figure 3 shows the in vitro release graphics. As it can be seen in Figure 3, $\mathrm{M}_{\mathrm{CEM}}$ and CEM solution shows $100 \%$ release at the end of the $7^{\text {th }}$ hour. 


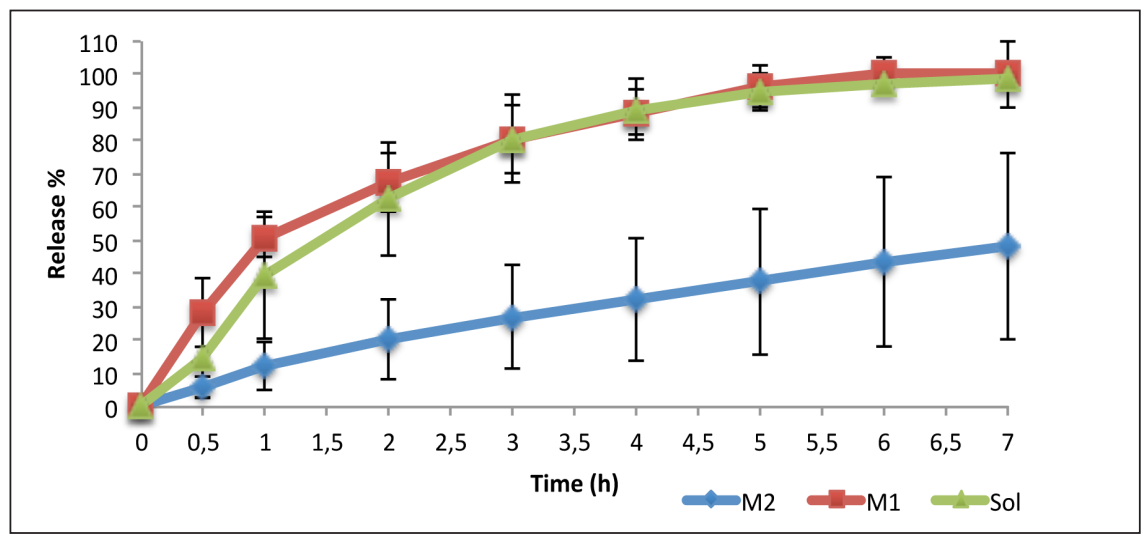

Figure 3. Percentage of release and time

\section{Evaluation of antibacterial activity studies of CEM loaded microemulsion formulations}

Table 3 shows the results of antibacterial activity tests of microemulsion formulations and their control groups which were performed on isolates of Staphylococcus epidermidis $\left(1 \mathrm{C} 1,7 \mathrm{~N}_{5}, 7 \mathrm{C} 5,7 \mathrm{N6}, 7 \mathrm{~K} 9,11 \mathrm{C} 8,11 \mathrm{~K} 8\right.$ and $\left.12 \mathrm{~K} 2.1\right)$, strains of S. epidermidis (ATCC 12228), S. aureus (ATCC 6538, ATCC 2593). As a result, it was noted that there was no zone when blank microemulsion formulations were applied to the bacteria tested. On the other hand, it was found that when the CEM loaded formulations were applied on the test bacteria, the zone diameters varied between 12 and $32 \mathrm{~mm}$.

When the CEM solution was applied on the bacteria alone, zone diameters were determined in between 16-32mm. Once the CEM loaded M1 and M2 microemulsion were applied on bacteria, zone diameter was measured between 12-30 mm, 18-28 mm, respectively. No zone formation was observed in the petri dishes in which the solvent was applied on.

As a result, blank M1 and M2 formulations were found to have no antibacterial activity when applied alone to the tested bacteria. In the meantime, CEM loaded M1 and M2 microemulsion was applied on the bacteria separately, it was seen that both of the formulations have close antibacterial activity compared to CEM solution. In addition, it was observed that the solvent used as a negative control in the study did not have any inhibitory effect on the bacteria. The study can be concluded that the M1 and M2 formulations could be used in combination with CEM antibiotic. Figure 4 shows the images of the zone diameters. At this figure, $\mathrm{G}_{1}, \mathrm{G}_{3}, \mathrm{G} 5$ refers to the above zones at each petri dish and G2, G4, G6 are for the below zones at each petri dish. 


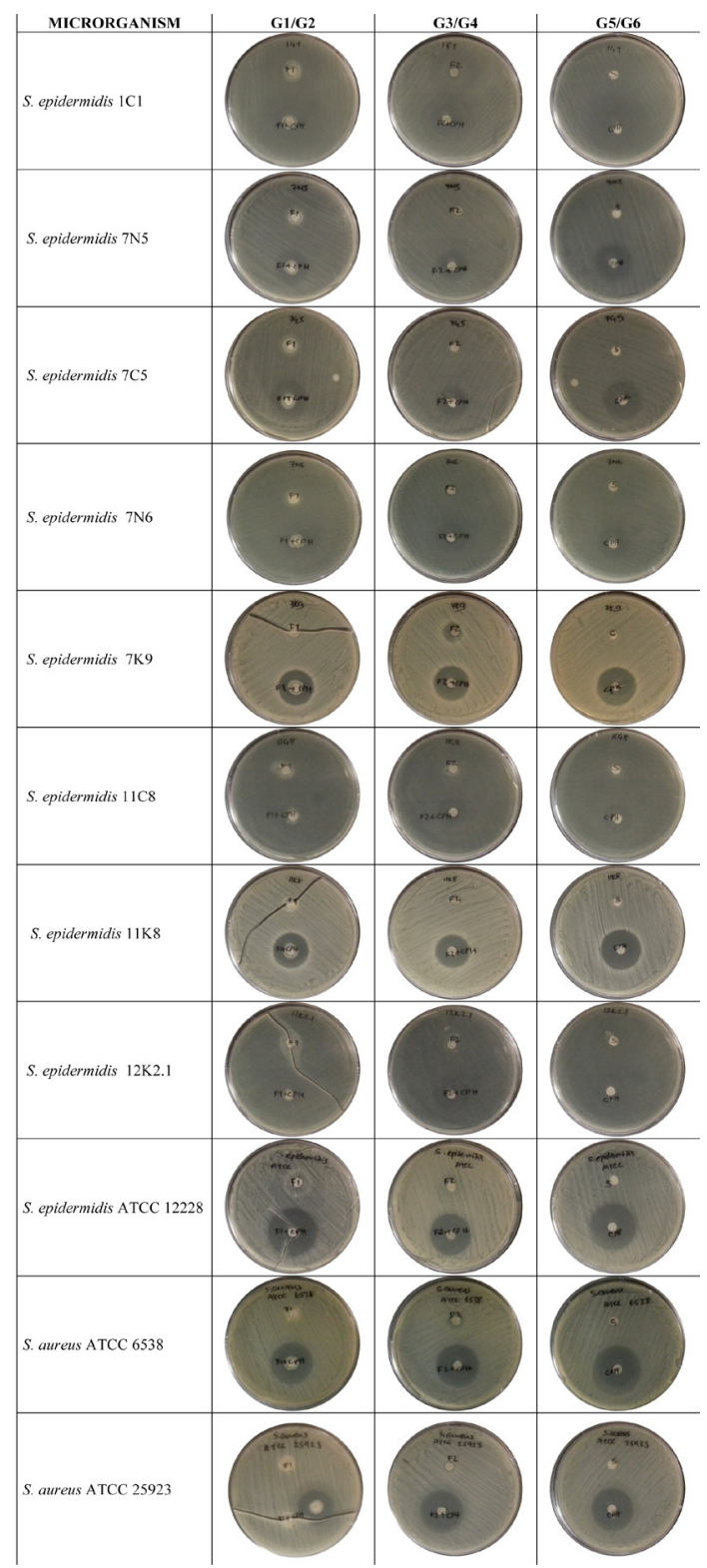

Figure 4. The images of zone diameters 
Table 3. Zone inhibition diameters

\begin{tabular}{|l|c|c|c|c|c|c|}
\hline \multirow{2}{*}{ MICR00RGANISMS } & \multicolumn{5}{|c|}{ DIAMETER of ZONE INHIBITION RING (mm) } \\
\cline { 2 - 7 } & G1 & G2 & G3 & G4 & G5 & G6 \\
\hline S. epidermidis 1C1 & - & 20 & - & 22 & 24 & - \\
\hline S. epidermidis 7N5 & - & 16 & - & 16 & 16 & - \\
\hline S. epidermidis 7C5 & - & 18 & - & 18 & 26 & - \\
\hline S. epidermidis 7N6 & - & 12 & - & 20 & 18 & - \\
\hline S. epidermidis 7K9 & - & 24 & - & 24 & 28 & - \\
\hline S. epidermidis 11C8 & - & 16 & - & 18 & 18 & - \\
\hline S. epidermidis 11K8 & - & 22 & - & 22 & 26 & - \\
\hline S. epidermidis 12K2.1 & - & 24 & - & 26 & 22 & - \\
\hline S. epidermidis ATCC 12228 & - & 30 & - & 26 & 30 & - \\
\hline S. aureus ATCC 6538 & - & 24 & - & 28 & 32 & - \\
\hline S. aureus ATCC 25923 & - & 18 & - & 26 & 26 & - \\
\hline
\end{tabular}

\section{CONCLUSION}

In this study, blank and CEM loaded microemulsions were prepared, characterized, and evaluated for in vitro drug release and microbiological activity. The pseudo ternary phase diagram was used to optimize the microemulsion formulations. The present study showed that CEM microemulsions can successfully be prepared with titration method with narrow particle size and PDI range. According to the results of the characterization, and in vitro release studies, both of the formulations can be used for the treatment. $\mathrm{M} 1_{\mathrm{CEM}}$ is a convenient formulation when prompt affect is required but on the other hand, if relatively prolonged release is necessary, $\mathrm{M}_{\text {CEM }}$ can be seen as a desirable formulation. The present study can open up a window for dermal application of microemulsions loaded with CEM; they would be a better alternative to conventional formulations in the treatment of various SSTIs with less systemic side-effects.

\section{ACKNOWLEDGEMENTS}

The authors would like to acknowledge thank DSM Sinochem, Spain for providing CEM as a kind gift.

\section{DECLARATION OF INTEREST}

The authors declare no conflict of interest. 


\section{REFERENCES}

1. Heuschkel S, Goebel A, Neubert RHH. Microemulsions-Modern Colloidal Carrier for Dermal and Transdermal Drug Delivery. J Pharm Sci. 2oo8, 97(2), 603-631.

2. Üstündağ Okur N, Çağlar EŞ, Arpa MD, Karasulu HY. Preparation and evaluation of novel microemulsion-based hydrogels for dermal delivery of benzocaine. Pharm Dev Technol. 2016, 7450(February), 1-11.

3. Schwarz JC, Weixelbaum A, Pagitsch E, Löw M, Resch GP, Valenta C. Nanocarriers for dermal drug delivery: Influence of preparation method, carrier type and rheological properties. Int J Pharm. 2012, 437(1), 83-88.

4. Lawrence MJ, Rees GD. Microemulsion-based media as novel drug delivery systems. Adv Drug Deliv Rev. 2000, 45(1), 89-121.

5. Neubert RHH. Potentials of new nanocarriers for dermal and transdermal drug delivery. Eur J Pharm Biopharm. 2011, $77(1), 1-2$.

6. Peltola S, Saarinen-Savolainen P, Kiesvaara J, Suhonen T., Urtti A. Microemulsions for topical delivery of estradiol. Int J Pharm. 2003, 254(2), 99-107.

7. Sintov AC, Botner S. Transdermal drug delivery using microemulsion and aqueous systems: Influence of skin storage conditions on the in vitro permeability of diclofenac from aqueous vehicle systems. Int J Pharm. 2006, 311(1), 55-62.

8. Üstündag-Okur N, Gökçe EH, Eğrilmez S, Özer Ö, Ertan G. Novel Ofloxacin-Loaded Microemulsion Formulations for Ocular Delivery. $J$ Ocul Pharmacol Ther. 2014, 3o(4), 319-332.

9. Ustündağ Okur N, Yavaşoğlu A, Karasulu HY. Preparation and evaluation of microemulsion formulations of naproxen for dermal delivery. Chem Pharm Bull. 2014, 62(2), 135-143.

10. Ustündağ Okur N, Apaydın S, Karabay Yavaşoğlu NÜ, Yavaşoğlu A, Karasulu HY. Evaluation of skin permeation and anti-inflammatory and analgesic effects of new naproxen microemulsion formulations. Int J Pharm. 2011, 416(1), 136-144.

11. Sammeta S, Vaka S, Murthy SN. Dermal Drug Levels of Antibiotic (Cephalexin) Determined by Electroporation and Transcutaneous Sampling (ETS) Technique. J Pharm Sci. 2009, 98(8), 2677-2685.

12. Ki V, Rotstein C. Bacterial skin and soft tissue infections in adults: A review of their epidemiology, pathogenesis, diagnosis, treatment and site of care. Can. J. Infect. Dis. Med. Microbiol. 2008, 19 (1712-9532 (Print)):173-184.

13. Del Rosso J. Therapeutic experience with cefdinir in the treatment of uSSSIs. Int $J$ Clin Pract. 2006, 6o(10), 1313-1316.

14. Wick WE. Cephalexin, a new orally absorbed cephalosporin antibiotic. Appl Microbiol. 1967, 15(4), 765-769. http://www.ncbi.nlm.nih.gov/pubmed/4383049. Accessed September 2, 2016.

15. Sneader W. Drug Discovery: A History. West Sussex, 2005.

16. Fanun M, Papadimitriou V, Xenakis A. Characterization of cephalexin loaded nonionic microemulsions. J Colloid Interface Sci. 2011, 361(1):115-121.

17. Karasulu HY, Oruc N, Ustundag-Okur N, et al. Aprotinin revisited: formulation, characterization, biodistribution and therapeutic potential of new aprotinin microemulsion in acute 
pancreatitis. $J$ Drug Target. 2015, (August):1-13.

18. Üstündag-Okur N, Gökçe EH, Eğrilmez S, Özer Ö, Ertan G. Novel Ofloxacin-Loaded Microemulsion Formulations for Ocular Delivery. J Ocul Pharmacol Ther. 2014, 30(4), 319-332.

19. Felten A, Grandry B, Lagrange PH, Casin I. Evaluation of Three Techniques for Detection of Low-Level Methicillin-Resistant Staphylococcus aureus ( MRSA ): a Disk Diffusion Method with Cefoxitin and Moxalactam, the Vitek 2 System, and the MRSA-Screen Latex Agglutination Test. 2002, $40(8)$, 2766-2771.

20. Junyaprasert VB, Boonme P, Songkro S, Krauel K, Rades T. Transdermal delivery of hydrophobic and hydrophilic local anesthetics from o/w and w/o Brij 97-based microemulsions. $J$ Pharm Pharm Sci (www cspsCanada.org). 2007, 10(3), 288-298. https://sites.ualberta. ca/ csps/JPPS10_3/MS_1180/MS_1180_Format_final.pdf. Accessed July 3, 2017.

21. Kaewnopparat S, Dangmanee N, Kaewnopparat N, Srichana T, Chulasiri M, Settharaksa S. In vitro probiotic properties of Lactobacillus fermentum $\mathrm{SK}_{5}$ isolated from vagina of a healthy woman. Anaerobe. 2013, 22, 6-13.

22. Gustaferro CA, Steckelberg JM. Cephalosporin Antimicrobial Agents and Related Compounds. Mayo Clin Proc. 1991, 66(10), 1064-1073.

23. Suman Panda S, Kumar BVVR, Dash R, Mohanta G. Sci Pharm Determination of Cephalexin Monohydrate in Pharmaceutical Dosage Form by Stability-Indicating RP-UFLC and UV Spectroscopic Methods. Panda) Sci Pharm Sci Pharm. 2013, 81(81), 1029-1041.

24. Lio PA, Kaye ET. Topical Antibacterial Agents. Med Clin North Am. 2011, 95(4), 703-721.

25. Spann CT, Tutrone WD, Weinberg JM, Scheinfeld N, Ross B. Topical antibacterial agents for wound care: A primer. Dermatologic Surg. 2003, 29(6), 620-626.

26. Schroeter A, Engelbrecht T, Neubert RHH, Goebel ASB. New nanosized technologies for dermal and transdermal drug delivery. A review. J Biomed Nanotechnol. 2010;6(5), 511-528.

27. Fenner JA, Wiss K, Levin NA. Oral Cephalexin for Acne Vulgaris: Clinical Experience with 93 Patients. Pediatr Dermatol. 2008, 25(2), 179-183.

28. Kreilgaard M. Influence of microemulsions on cutaneous drug delivery. Adv Drug Deliv Rev. 2002, 54(SUPPL.)

29. Naik A, Kalia YN, Guy RH. Transdermal drug delivery : overcoming the skin 's barrier function. Pstt. 200o, 3(9), 318-326.

30. Patel J, Patel A, Raval M, Sheth N. Formulation and development of a self-nanoemulsifying drug delivery system of irbesartan. $J$ Adv Pharm Technol Res. 2011, 2(1), 9-16. 